\title{
Homeobox A10 promotes the proliferation and invasion of bladder cancer cells via regulation of matrix metalloproteinase-3
}

\author{
CHUNLEI LIU ${ }^{1 *}$, MINGZHU GE ${ }^{2 *}$, JUN MA ${ }^{1 *}$, YANHUI ZHANG ${ }^{1}$, YANHUI ZHAO $^{1}$ and TAO CUI ${ }^{1}$ \\ Departments of ${ }^{1}$ Urology and ${ }^{2}$ Ultrasound, Qingdao Central Hospital, Qingdao, Shandong 266042, P.R. China
}

Received February 9, 2018; Accepted January 31, 2019

DOI: $10.3892 / \mathrm{ol} .2019 .10312$

\begin{abstract}
Homeobox A10 (HOXA10) belongs to the family of HOX genes, which are closely connected with embryonic development and serve important roles in various tumors. However, the role of HOXA10 in bladder cancer (BC) remains unclear. In the present study, the role of HOXA10 in BC and the underlying mechanisms by which it promotes the disease progression were investigated. Immunohistochemical analysis demonstrated that the expression of the HOXA10 protein was significantly higher in $\mathrm{BC}$ tissues as compared with that in adjacent normal tissues. Subsequent statistical analysis revealed that upregulation of HOXA10 was significantly associated with the pathological grade and clinical stage of BC patients. In the BC cell lines T24 and 5637, silencing of HOXA10 by small interfering RNA transfection suppressed the proliferation, migration and invasion of $\mathrm{BC}$ cells, and led to decreased matrix metalloproteinase- 3 expression. Taken together, overexpression of HOXA10 may be associated with poor prognosis in $\mathrm{BC}$, and may serve as a novel antitumor therapy target for the treatment of this disease.
\end{abstract}

\section{Introduction}

Bladder cancer (BC) is the most common malignancy of the urinary system and its incidence presents an increasing trend (1). Urothelial carcinoma is the most common subtype of bladder cancer and is categorized as muscle invasive or non-muscle invasive (2). Despite the advances in surgical techniques and the use of chemotherapy as a treatment option, a great number of patients experience little clinical benefit due to the likelihood of recurrence and early tumor infiltration (3).

Correspondence to: Dr Yanhui Zhao or Dr Tao Cui, Department of Urology, Qingdao Central Hospital, 127 Si Liu Nan Road, Qingdao, Shandong 266042, P.R. China

E-mail: 19341063@qq.com

E-mail: 873395630@qq.com

\section{*Contributed equally}

Key words: homeobox A10, bladder cancer, cell invasion, matrix metalloproteinase-3
Smoking and obesity are risk factors for BC (2), and genetic mutations and abnormal protein expression serve important roles in the genesis, development and progression of BC (4). Therefore, exploring new anomalous molecules involved in the development of BC may advance the understanding of the mechanisms behind this disease and contribute to the improvement of treatment strategies.

Homeobox A10 (HOXA10) belongs to the family of HOX genes, which are classified into four subgroups, namely HOX A-D (5), and are closely connected with embryonic development (6). HOXA10 encodes a DNA-binding transcription factor that serves vital roles in regulating gene expression, viability and differentiation of cells in the embryo and morphogenesis. An increasing number of studies have demonstrated that HOX genes, including HOXA10, serve important roles in oncology and in the development of various tumors (7). Previous studies have identified abnormal HOXA10 expression and reported the cancer-promoting activities of HOXA10 in various malignant disorders, including endometrial, nasopharyngeal, gastric and breast cancer (7-11). However, the expression and role of HOXA10 in BC has not been previously reported.

Based on the abnormal expression and cancer-promoting roles of HOXA10 in the development of various cancers, we hypothesized that HOXA10 may play vital roles in the development of BC. Initially, immunohistochemistry was used to determine the expression of HOXA10 in BC and adjacent normal tissues. After revealing the high expression level of HOXA10 in BC, cell proliferation, migration and invasion assays were performed in T24 and 5637 cells with HOXA10 knocked down by small interfering RNA (siRNA). Furthermore, western blotting analysis was carried out to explore the mechanism by which HOXA10 promotes BC progression and facilitates the malignant behavior of $\mathrm{BC}$ cells.

\section{Materials and methods}

Patients and specimens. A total of 78 paired fresh specimens of $\mathrm{BC}$ and adjacent normal tissues) were obtained from patients diagnosed with $\mathrm{BC}$ and underwent total cystectomy in Qingdao Central Hospital (Qingdao, China) between March 2011 and August 2015. None of the patients underwent any preoperative therapy, such as chemotherapy or radiation therapy. The exclusion criteria also included presence of tumors with histologically identified extensive necrosis. The diagnosis and pathological grades of the patients were verified 
using hematoxylin and eosin (H\&E) staining, according to the World Health Organization classification guidelines (12). Patients were assigned to three pathological grades (GI-III) according to the differential degree of tumor differentiation (12), and the patient population included 17, 25 and 36 cases with a pathological grade of I, II and III, respectively. The clinical stage of BC patients was determined according to the American Joint Committee on Cancer guidelines (13), including stages I, II, III and IV. The patient population in the present study consisted of 38 and 40 cases with clinical stages of I+II and III+IV, respectively. All patients agreed to the use of their samples in the present study and signed an informed consent prior to surgery. The current study was approved by the Ethical Reviewing Committee of Qingdao Central Hospital. Patient characteristics are listed in Table I.

Immunohistochemical analysis. HOXA10 expression was detected in the 78 paired fresh specimens using immunohistochemistry. Briefly, the fresh specimens were fixed in $10 \%$ formalin for $24 \mathrm{~h}$ at room temperature and routinely processed for paraffin embedding. Serial histologic sections were cut to a thickness of $4 \mu \mathrm{m}$, initially stained with hematoxylin for $5 \mathrm{~min}$ and eosin for $1 \mathrm{~min}$ at room temperature, and then analyzed by a senior pathologist to identify the diagnosis and pathological grades of the patients. Subsequent to dewaxing and rehydration, the sections were washed three times with $1 \mathrm{X}$ phosphate-buffered saline ( $5 \mathrm{~min} / \mathrm{wash}$ ). Next, the sections were blocked with normal goat serum for $25 \mathrm{~min}$ at room temperature and subsequently incubated with HOXA10 monoclonal antibodies (1:50 dilution; Santa Cruz Biotechnology, Inc., Santa Cruz, CA, USA) in a moisture chamber overnight at $4^{\circ} \mathrm{C}$. Following incubation, immunodetection was performed using the Envision $\mathrm{ABC}$ kit (Genetech Co., Ltd., Shanghai, China). Subsequently, the HOXA10 staining score of the specimens was assigned as previously described (9). Initially, the staining intensity score was assigned as follows: 0 , negative staining; 1 , weak staining; 2 , moderate staining; and 3 , strong staining. In addition, the percentage of stained tumor cells was scored as follows: 0 , negative; $1,1-10 \% ; 2,10-50 \% ; 3,50-80 \%$; and 4, 80-100\%. The HOXA10 staining score was then calculated as the sum of the scores for the staining intensity and percentage of stained tumor cells. Finally, BC and adjacent normal tissues were categorized into the high HOXA10 expression group when the total staining score was 5-7 and the low HOXA10 expression group when the score was 0-4.

Cell lines and cell culture. T24 and 5637 cell lines were used in the current study. The two cell lines were purchased from the American Type Culture Collection (Manassas, VA, USA) and cultured in RPMI-1640 medium (Gibco; Thermo Fisher Scientific, Inc., Waltham, MA, USA), supplemented with 10\% fetal bovine serum (Gibco; Thermo Fisher Scientific, Inc., Sydney, Australia) and 1\% penicillin/streptomycin (both Gibco; Thermo Fisher Scientific, Inc.). Cells were cultured in a humidified atmosphere at $5 \% \mathrm{CO}_{2}$ and $37^{\circ} \mathrm{C}$.

Cell transfection. In order to silence HOXA10 expression in the BC cell lines, an siRNA targeting HOXA10 (si-HOXA10) and a control siRNA (si-Ctrl) were constructed by GenePharma Co.,
Ltd., (Suzhou, China). The siRNA sequences were as follows: si-HOXA10, 5'-CACGGACAGACAAGTGAAATT-3' (sense) and 5'-GTGCCTGTCTGTGTTCACTTTTT-3' (antisense); si-Ctrl, 5'-UUCUCCGAACGUGUCACGUTT-3' (sense) and 5'-ACGUGACACGUUCGGAGAATT-3' (antisense). T24 and 5637 cells were transfected with the siRNAs using Lipofectamine ${ }^{\circledR} 2000$ (Invitrogen; Thermo Fisher Scientific, Inc.) according to the manufacturer's protocol. Western blotting was subsequently used to assess the silencing efficiency of si-HOXA10. Initially, the silencing efficiency of si-HOXA10 on HOXA10 expression in T24 and 5637 cells compared with si-Ctrl and untreated control groups was detected. As si-Ctrl had little effect on HOXA10 and was similar to the untreated group, cells were treated only using si-HOXA10 and si-Ctrl in subsequent experiments.

Western blotting. Cells were lysed for $30 \mathrm{~min}$ on ice using radioimmunoprecipitation assay buffer (Beijing Solarbio Science \& Technology Co., Ltd., Beijing, China), and total protein was quantified using the BCA Protein Assay kit (Beijing Solarbio Science \& Technology Co., Ltd.) according to the manufacturer's protocol. For western blot analysis, a total of $20 \mu \mathrm{g}$ total protein was loaded per lane and separated in a $12 \%$ gel by SDS-PAGE. Subsequent to transferring the proteins onto a nitrocellulose membrane (EMD Millipore, Billerica, MA,USA), the membrane was blocked with 5\% fat-free milk for $1.5 \mathrm{~h}$ at room temperature and incubated with primary antibodies at $4^{\circ} \mathrm{C}$ overnight. The primary antibodies used in the present study were as follows: Anti-HOXA10 monoclonal antibody (cat. no. sc-271428; 1:500 dilution; Santa Cruz Biotechnology, Inc.); and anti-MMP-3 (cat. no. 14351), anti-MMP-2 (cat. no. 40994), anti-MMP-7 (cat. no. 3801), anti-MMP-9 (cat. no. 15561) and anti-GAPDH (cat. no. 2118) monoclonal antibodies (all 1:1,000 dilution), obtained from Cell Signaling Technology, Inc., (Danvers, MA, USA). Next, the membrane was incubated with goat anti-rabbit $\operatorname{IgG}(\mathrm{H}+\mathrm{L})$ horseradish peroxidase-conjugated secondary antibody for $2 \mathrm{~h}$ at room temperature (cat. no. GAR0072; 1:5,000 dilution; Multisciences Lianke Biotech Co., Ltd., Hangzhou, China). Subsequently, the proteins were detected by enhanced chemiluminescence using a chemiluminescent and fluorescent imaging system (Sagecreation, Hangzhou, China). GAPDH was used as an internal control.

Cell proliferation assays. Subsequent to cell transfection with siRNAs for $24 \mathrm{~h}$, a total of $1.5 \times 10^{3}$ cells in $200 \mu \mathrm{l}$ RPMI-1640 medium were seeded into 96 -well plates and maintained for 5 days. Between days 1 and 5, cell proliferation was examined by measuring the absorbance of the cells using a Cell Counting Kit-8 (CCK-8; Dojindo Molecular Technologies, Inc., Kumamoto, Japan), according to the manufacturer's protocol. The experiment was conducted in triplicate at each time point.

Cell migration and invasion assay. For cell migration assays, $4 \times 10^{4}$ cells were transfected with siRNAs for $24 \mathrm{~h}$ in $200 \mu \mathrm{l}$ serum-free medium and then placed into the upper chambers of 24-well plates with Transwell insert (Corning, Inc., Corning, NY, USA). For cell invasion assays, $4 \times 10^{4}$ cells were transfected with siRNAs for $24 \mathrm{~h}$ in $200 \mu 1$ serum-free medium 
Table I. Association between HOXA10 expression and clinical features of patients with BC.

\begin{tabular}{|c|c|c|c|c|}
\hline \multirow[b]{2}{*}{ Characteristics } & \multirow[b]{2}{*}{ No. } & \multicolumn{2}{|c|}{ Expression of HOXA10 } & \multirow[b]{2}{*}{ P-value } \\
\hline & & Low & High & \\
\hline Tissue type & & & & 0.035 \\
\hline Normal adjacent & 78 & 48 & 30 & \\
\hline $\mathrm{BC}$ & 78 & 35 & 43 & \\
\hline Pathological grade & & & & 0.005 \\
\hline I+II & 42 & 25 & 17 & \\
\hline III & 36 & 10 & 26 & \\
\hline Clinical stage & & & & 0.006 \\
\hline $\mathrm{I}+\mathrm{II}$ & 38 & 23 & 15 & \\
\hline III+IV & 40 & 12 & 28 & \\
\hline Gender & & & & 0.382 \\
\hline Male & 66 & 31 & 35 & \\
\hline Female & 12 & 4 & 8 & \\
\hline Age (years) & & & & 0.893 \\
\hline$\geq 70$ & 43 & 19 & 24 & \\
\hline$<70$ & 35 & 16 & 19 & \\
\hline Size $(\mathrm{cm})$ & & & & 0.710 \\
\hline$\geq 4$ & 33 & 14 & 19 & \\
\hline$<4$ & 45 & 21 & 24 & \\
\hline Lymph node metastasis & & & & 0.176 \\
\hline Yes & 31 & 11 & 20 & \\
\hline No & 47 & 24 & 23 & \\
\hline
\end{tabular}

HOXA10, homeobox A10; BC, bladder cancer.

and then placed in the upper chambers of a Transwell insert that contained a layer of Matrigel (Corning, Inc.). The bottom chamber of each well was filled with $700 \mu$ l conditioned medium. After 24-h incubation, the cells that had adhered to the filter were fixed with $4 \%$ paraformaldehyde for $20 \mathrm{~min}$, following the removal of non-migrating and non-invading cells remaining in the upper chamber. The migrating and invading cells were then stained with $1 \%$ crystal violet for $20 \mathrm{~min}$, following which cells were counted and images were captured at a magnification of $\mathrm{x} 200$. Each experiment was conducted in triplicate.

Statistical analysis. All data were analyzed using SPSS software (v.19.0; IBM Corporation, Armonk, NY, USA), and are presented as the mean \pm standard error of the mean. $\chi^{2}$ tests were used to determine the association between HOXA10 expression and the clinicopathological features of patients. Differences between the si-HOXA10 and si-Ctrl groups were analyzed using Student's t-test. $\mathrm{P}<0.05$ was considered to indicate a statistically significant difference.

\section{Results}

HOXA10 is overexpressed in BC tissues. To analyze HOXA10 expression in $\mathrm{BC}$, HOXA10 protein expression was detected in $\mathrm{BC}$ and adjacent normal tissues by immunohistochemical analysis. The results demonstrated that HOXA10 expression was upregulated in BC tissues as compared with that in adjacent normal tissues (Fig. 1). High HOXA10 protein expression was identified in 55.1\% (43/78) of BC tissues and 38.5\% (30/78) of adjacent normal tissues $(\mathrm{P}=0.035$; Table $\mathrm{I})$, which suggests that HOXA10 is upregulated in BC.

HOXA10 expression is associated with specific clinicopathological features of patients with BC. As shown in Table I, the expression level of HOXA10 was significantly associated with the pathological grade $(\mathrm{P}=0.005)$ and clinical stage $(\mathrm{P}=0.006)$ of the patients. However, no significant associations were identified between HOXA10 expression and the patient gender $(\mathrm{P}=0.382)$, age $(\mathrm{P}=0.893)$, tumor size $(\mathrm{P}=0.710)$ or lymph node metastasis $(\mathrm{P}=0.176)$. These results revealed that HOXA10 may be a biomarker for evaluating the progression of $\mathrm{BC}$.

HOXA10 silencing inhibits the proliferation of $B C$ cells. To investigate the effect of HOXA10 on the proliferation of $\mathrm{BC}$ cells, in vitro proliferation assays were performed using a CCK-8 Kit at different time points. As shown in Fig. 2A, HOXA10 expression was successfully downregulated in T24 and 5637 cells by si-HOXA10 transfection. Next, the cell growth curves indicated that silencing of HOXA10 significantly inhibited BC cell proliferation at 48, 72 and 

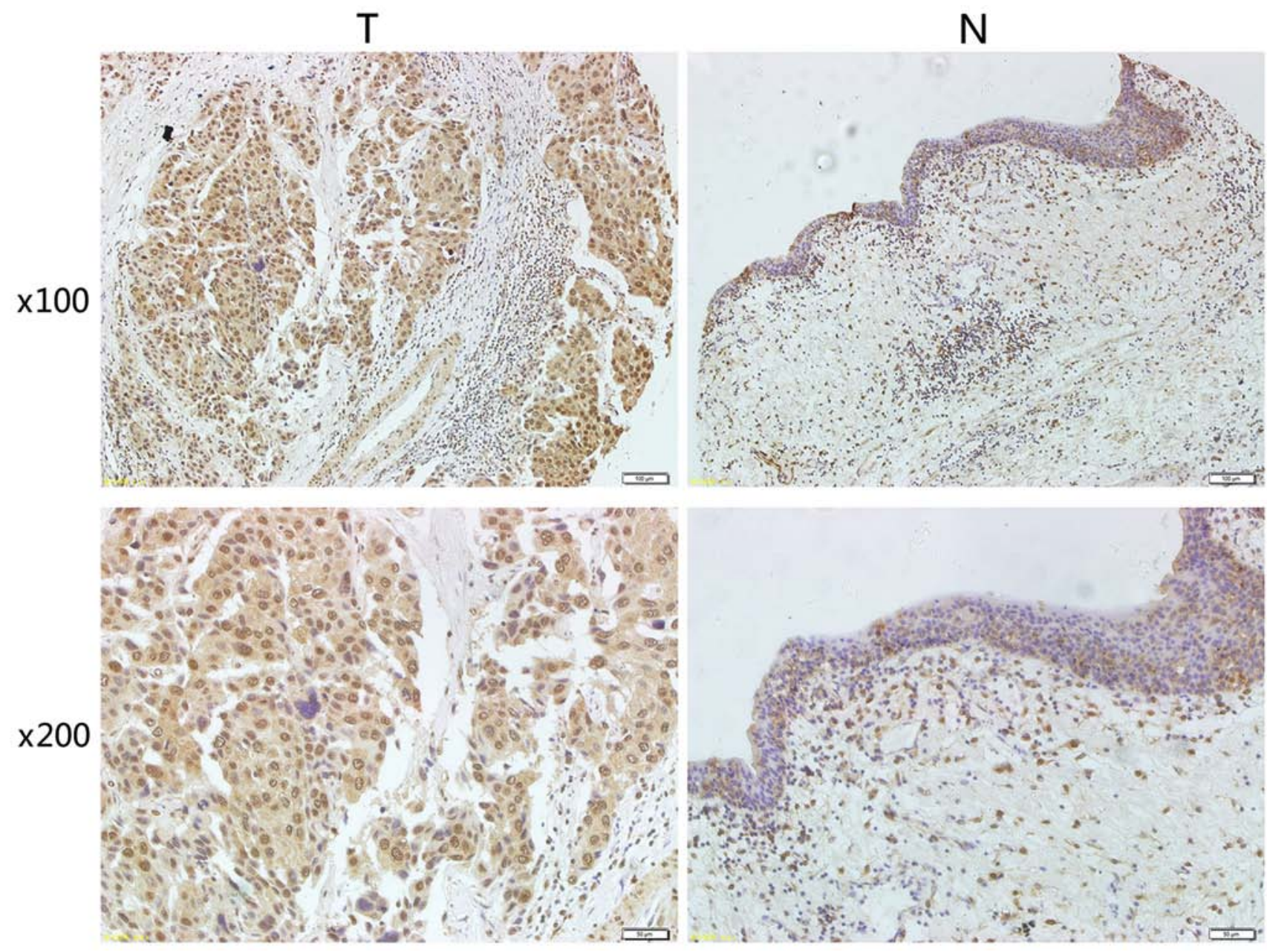

Figure 1. Expression of HOXA10 was evidently upregulated in bladder cancer tissues compared with that in paired normal renal tissue, as observed by immunohistochemical analysis (magnification, x100 and x200). HOXA10, homeobox A10; T, tumor tissue; N, normal tissue.

$96 \mathrm{~h}$ of incubation, as compared with the control group (Fig. 2B). These results implied that HOXA10 participates in the proliferation of $\mathrm{BC}$ cells, therefore supporting the hypothesis that HOXA10 may serve as novel target for BC treatment.

HOXA10 silencing significantly suppresses the migration and invasion abilities of $B C$ cells. Due to the important roles of cell migration and invasion in BC metastasis, the current study next performed migration and invasion assays to investigate the effect of HOXA10 on BC cells. As shown in Figs. 3 and 4, the number of migrating and invading cells transfected with si-HOXA10 was significantly reduced when compared with that in the group transfected with si-Ctrl. These findings indicated that HOXA10 silencing lowered the invasion and migration abilities of $\mathrm{BC}$ cells.

HOXA10 silencing reduces the expression of MMP-3. To explore HOXA10-associated mechanisms involved in the progression of BC, protein expression in T24 and 5637 cells was analyzed using western blotting. As demonstrated in Fig. 5, the MMP-3 expression levels were suppressed in the HOXA10-silencing group compared with those the control group. However, the expression of MMP-2, MMP-7 and MMP-9 were not evidently changed.

\section{Discussion}

Recently, studies have demonstrated that HOX genes serve pivotal roles in the occurrences and development of various types of cancer (7-11). Different members of the HOX gene family serve different roles in the promotion of carcinogenesis, and even individual members can have diverse roles in different tumors. It has previously been reported that HOXB13 was associated with the occurrence and progression of $\mathrm{BC}$, and had the ability to differentiate between the non-muscle invasive BC and muscle invasive BC phenotypes (14). In cervical cancer, homeobox family genes HOXA1, HOXC5, HOXC6, HOXC8 and HOXD9 were involved in the process of carcinogenesis, while HOXB2, HOXB4, HOXB13 and HOXC11-13 were involved in the malignant transformation of cervical epithelial cells (15). However, HOXC9 and HOXD12 were not expressed in any cervical tissues, which indicated that they did not particulate in the development of cervical cancer (16).

An increasing number of studies have demonstrated that HOXA10 is abnormally expressed in a variety of tumors, promotes the malignant behavior of cancer cells and influences the prognosis of patients (17-19). However, methylation of the HOXA10 promoter in endometrial cancer revealed that HOXA10 has an effect on carcinogenesis (20). Therefore, 
A

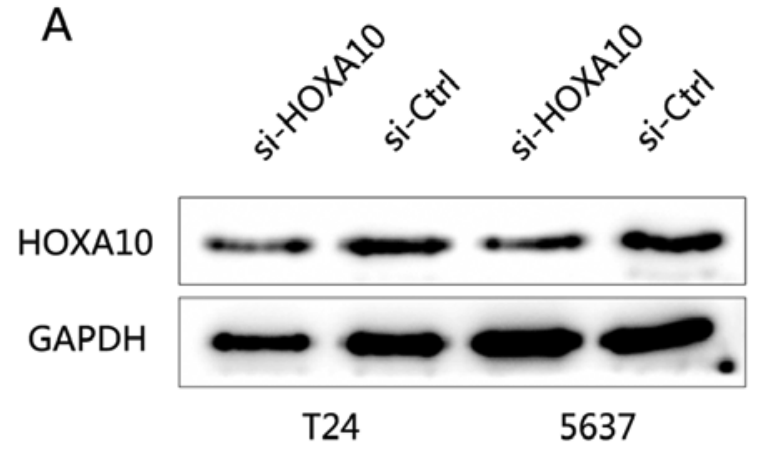

B

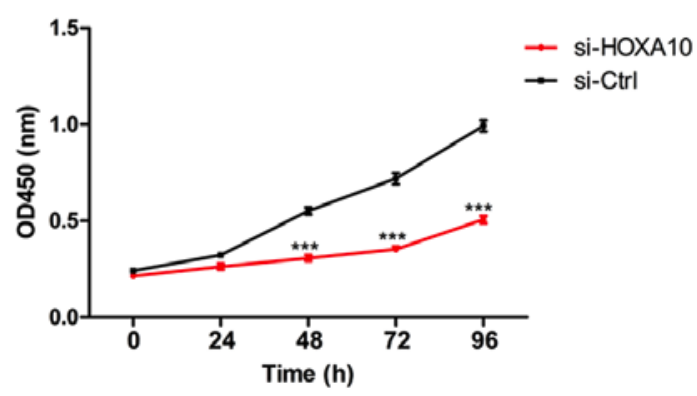

5637

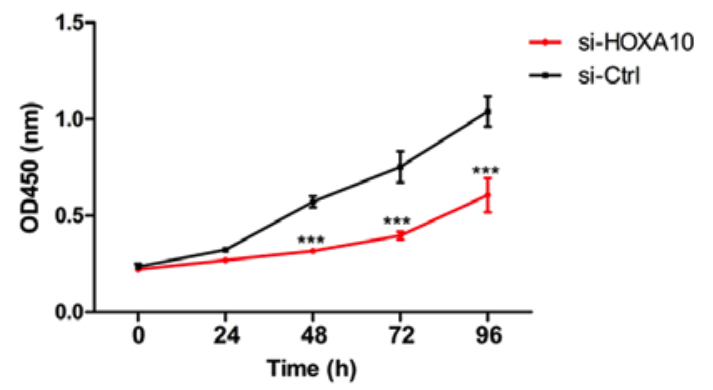

Figure 2. HOXA10 silencing inhibited the proliferation of bladder cancer cells. (A) HOXA10 protein expression in T24 and 5637 cells was downregulated following silencing by transfection with si-HOXA10. (B) Cell Counting Kit-8 assays indicated that the proliferation of cells infected with si-HOXA10 was inhibited compared with that in cells infected with si-Ctrl. ${ }^{* * *} \mathrm{P}<0.001$. HOXA10, homeobox A10; si-, small interfering RNA; Ctrl, control; OD, optical density.
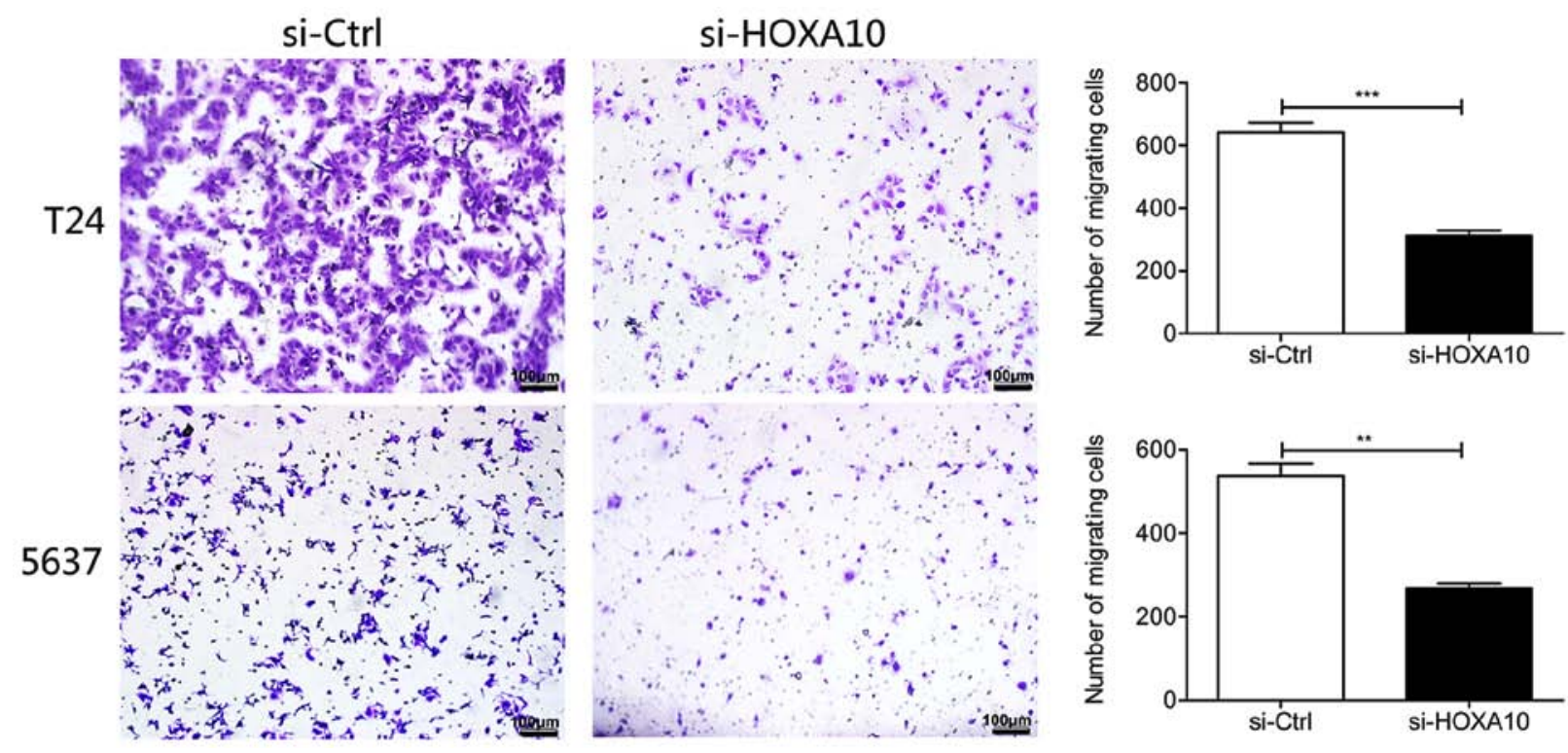

Figure 3. HOXA10 silencing inhibited the migration ability of bladder cancer cells. The number of migrating cells in the si-HOXA10 group was reduced compared with that in the si-Ctrl group. ${ }^{* *} \mathrm{P}<0.01$ and ${ }^{* * *} \mathrm{P}<0.001$. HOXA10, homeobox A10; si-, small interfering RNA; Ctrl, control.

in-depth investigation of HOXA10 may provide new perspectives on tumor detection, development and treatment.

Multiple previous studies exploring tumorigenesis and progression identified a series of abnormal genes in BC (21-23). In the present study, it was observed that HOXA10 was overexpressed in $\mathrm{BC}$ tissues and contributed to the malignant behavior of $\mathrm{BC}$ cells. In addition, it was confirmed that HOXA10 regulated the expression of MMP-3, which may promote the invasion of $\mathrm{BC}$ cells. The present study also indicated that HOXA10 expression in BC tissues was associated with the clinicopathological features of patients, suggesting that HOXA10 may be involved in the pathological progression of BC. However, previous studies reported that HOXA10 expression was low in endometrial and ovarian cancer $(20,24)$, which is contrary to the present study results, and indicates the different roles and underlying mechanisms of HOXA10 in different types of cancer.

Although it was demonstrated that HOXA10 expression was higher in $\mathrm{BC}$ tissues compared with that in adjacent normal tissues, the current study failed to analyze the 

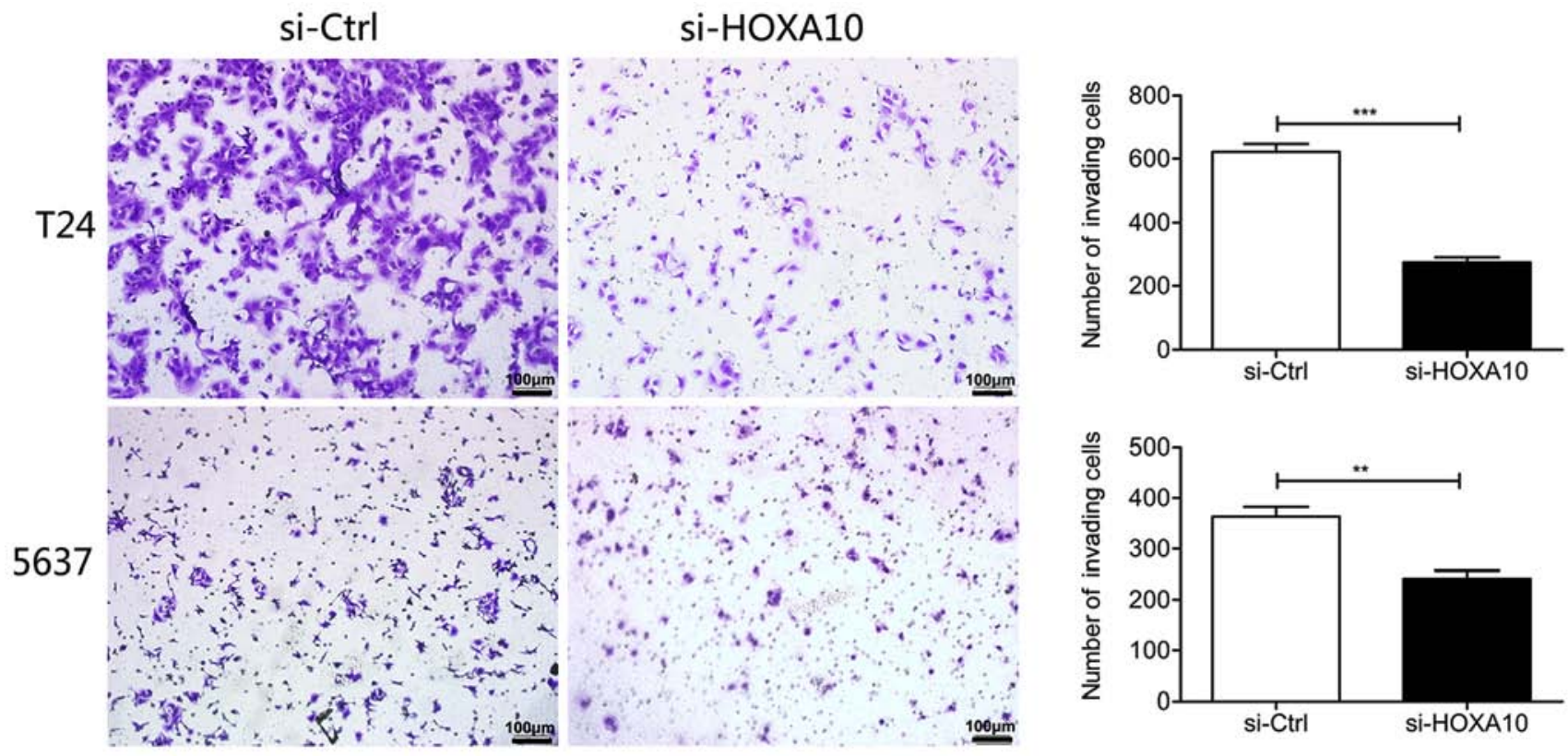

Figure 4. HOXA10 silencing inhibited the invasion ability of bladder cancer cells. The number of invading cells in the si-HOXA10 groups was reduced compared with that in the si-Ctrl group. ${ }^{* *} \mathrm{P}<0.01$ and ${ }^{* * * *} \mathrm{P}<0.001$. HOXA10, homeobox A10; si-, small interfering RNA; Ctrl, control.

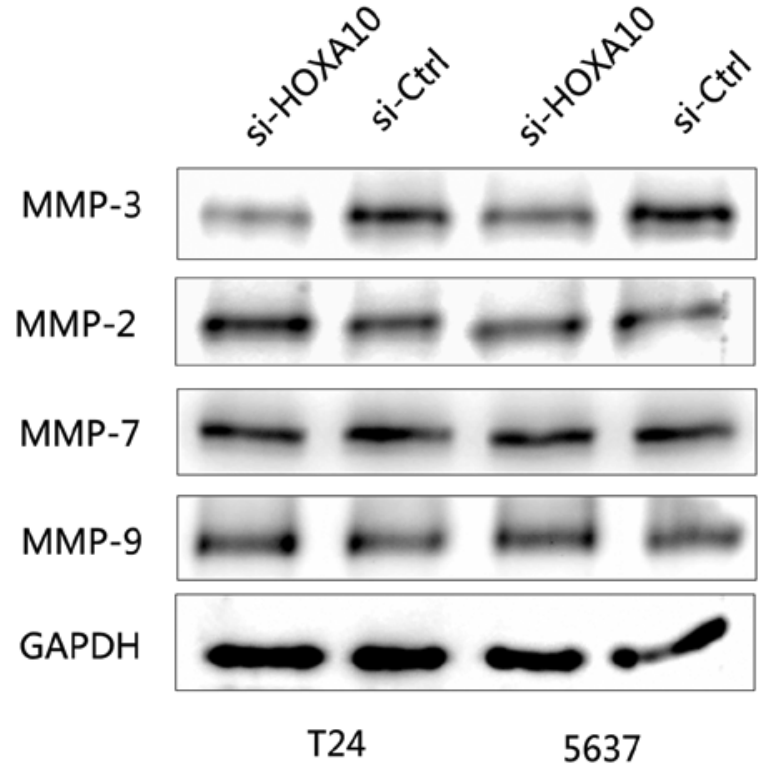

Figure 5. HOXA10 silencing repressed the protein expression of MMP-3 in T24 and 5637 bladder cancer cell lines. The expression levels of MMP-2, -7 and -9 were not evidently changed. HOXA10, homeobox A10; MMP, matrix metalloproteinase; si-, small interfering RNA; Ctrl, control.

association between HOXA10 expression and the prognosis of patients with $\mathrm{BC}$ due to the small number of cases and limited patient information. Therefore, subsequent studies should include an increased number of patients and data obtained in the follow-up, and analyze more disease-associated proteins to further elucidate the role of HOXA10. For instance, the correlation of HOXA10 with CD44 and P53 can be further examined, which have already been investigated in gastric and breast cancer $(9,11)$.

A combination of gene mutations and abnormal expression levels of proteins were involved in the development of
BC. In-depth investigation of these mutations or abnormal expression profiles may elucidate the pathways that cause BC. By knocking down HOXA10 expression in the current study, MMP-3 expression was evidently decreased in BC cells. MMP-3 belongs to the MMP family, members of which have been reported to be overexpressed in $\mathrm{BC}$, and to promote the infiltration of $\mathrm{BC}$ cells by degrading the extracellular matrix and basement membrane $(25,26)$.

Although lymph node metastasis of BC cells is associated with various factors, such as mutations of a number of genes involved in $\mathrm{BC}$ progression, the current study revealed that the expression of HOXA10 was not associated with lymph node metastasis, which may be due to the small number of BC specimens included. Nevertheless, the results indicated that HOXA10 may promote the invasion and metastasis of $\mathrm{BC}$ cells by regulating MMP-3 expression, as demonstrated in cells subjected to HOXA10 silencing. Although previous studies have demonstrated that other MMPs, including MMP-2, MMP-9 and MMP-7, were overexpressed and involved in the progression of BC (27-29), the present study found no evident change in the expression levels of these MMPs following HOXA10 silencing in BC cell lines. Therefore, future studies should focus on the mechanisms underlying the regulation of MMP-3 by HOXA10 and the effect of HOXA10 overexpression on BC cell behavior. Furthermore, HOXA10 has been reported to be regulated by various miRNAs in different tumors and to be involved in different signaling pathways $(19,30,31)$, which may be an important study direction in the future.

In conclusion, upregulation of HOXA10 may not only promote the proliferation, migration and invasion of $\mathrm{BC}$ cells, but also be associated with advanced pathological grade and clinical stage in BC. Therefore, HOXA10 may be a suitable biomarker for evaluating the progression of $\mathrm{BC}$ and a potential target for targeted therapy in patients with $\mathrm{BC}$. 


\section{Acknowledgements}

Not appicable.

\section{Funding}

No funding was received.

\section{Availability of data and materials}

The datasets used and/or analyzed during the present study are available from the corresponding author on reasonable request.

\section{Authors' contributions}

CL and MG performed the experiments, analyzed the data and drafted the manuscript. JM contributed to the conception of the study and participated in the revision of the manuscript. YZhang participated in the collection of specimens and interpretation of data. YZhao and TC were responsible for the design of the study and funded it.

\section{Ethics approval and consent to participate}

All experiments were approved by the Ethical Reviewing Committee of Qingdao Central Hospital (Qingdao, China). All participants signed informed consent prior to surgery.

\section{Patient consent for publication}

Not applicable.

\section{Competing interests}

The authors declare that they have no competing interests.

\section{References}

1. Babjuk M: Trends in bladder cancer incidence and mortality: Success or disappointment? Eur Urol 71: 109-110, 2017.

2. Wyszynski A, Tanyos SA, Rees JR, Marsit CJ, Kelsey KT, Schned AR, Pendleton EM, Celaya MO, Zens MS, Karagas MR and Andrew AS: Body mass and smoking are modifiable risk factors for recurrent bladder cancer. Cancer 120: 408-414, 2014.

3. Moschini M, Dell'Oglio P, Luciano R, Gandaglia G, Soria F, Mattei A, Klatte T, Damiano R, Shariat SF, Salonia A, et al: Incidence and effect of variant histology on oncological outcomes in patients with bladder cancer treated with radical cystectomy. Urol Oncol 35: 335-341, 2017.

4. Tang C, Guo J, Chen H, Yao CJ, Zhuang DX, Wang Y, Tang WJ, Ren G, Yao Y, Wu JS, et al: Gene mutation profiling of primary glioblastoma through multiple tumor biopsy guided by $1 \mathrm{H}$-magnetic resonance spectroscopy. Int J Clin Exp Pathol 8: 5327-5335, 2015.

5. Chen KN, Gu ZD, Ke Y, Li JY, Shi XT and Xu GW: Expression of $11 \mathrm{HOX}$ genes is deregulated in esophageal squamous cell carcinoma. Clin Cancer Res 11: 1044-1049, 2005.

6. Jiang R, Ding L, Zhou J, Huang C, Zhang Q, Jiang Y, Liu J, Yan Q, Zhen X, Sun J, et al: Enhanced HOXA10 sumoylation inhibits embryo implantation in women with recurrent implantation failure. Cell Death Discov 3: 17057, 2017.

7. Yoshida H, Broaddus R, Cheng W, Xie S and Naora H: Deregulation of the HOXA10 homeobox gene in endometrial carcinoma: Role in epithelial-mesenchymal transition. Cancer Res 66: 889-897, 2006.
8. Shen ZH, Zhao KM and Du T: HOXA10 promotes nasopharyngeal carcinoma cell proliferation and invasion via inducing the expression of ZIC2. Eur Rev Med Pharmacol Sci 21: 945-952, 2017.

9. Han Y, Lu S, Wen YG, Yu FD, Zhu XW, Qiu GQ, Tang HM, Peng ZH and Zhou CZ: Overexpression of HOXA10 promotes gastric cancer cells proliferation and HOXA10(+)/CD44(+) is potential prognostic biomarker for gastric cancer. Eur J Cell Biol 94: 642-652, 2015.

10. Park SM, Choi EY, Bae M, Choi JK and Kim YJ: A long-range interactive DNA methylation marker panel for the promoters of HOXA9 and HOXA10 predicts survival in breast cancer patients. Clin Epigenetics 9: 73, 2017.

11. Chu MC, Selam FB and Taylor HS: HOXA10 regulates p53 expression and matrigel invasion in human breast cancer cells. Cancer Biol Ther 3: 568-572, 2004.

12. van de Putte EEF, Bosschieter J, van der Kwast TH, Bertz S, Denzinger S, Manach Q, Compérat EM, Boormans JL, Jewett MAS, Stoehr R, et al: The World Health Organization 1973 classification system for grade is an important prognosticator in T1 non-muscle-invasive bladder cancer. BJU INT 122: 978-985, 2018.

13. Zarei S, Frank I, Boorjian SA, Thompson RH, Kim S, Weight C, Tarrell R, Thapa P and Cheville JC: Prognostic significance of measured depth of invasion of urothelial carcinoma of the bladder compared to the 2010 American joint committee on cancer pT2 and pT3 classifications. J Urol 188: 1706-1711, 2012.

14. Marra L, Cantile M, Scognamiglio G, Perdonà S, La Mantia E, Cerrone M, Gigantino V, Cillo C, Caraglia M, Pignata S, et al: Deregulation of HOX B13 expression in urinary bladder cancer progression. Curr Med Chem 20: 833-839, 2013.

15. Lopez-Romero R, Marrero-Rodriguez D, Romero-Morelos P Villegas V, Valdivia A, Arreola H, Huerta-Padilla V and Salcedo M: The role of developmental HOX genes in cervical cancer. Rev Med Inst Mex Seguro Soc 2 (Suppl 53): S188-S193, 2015 (In Spanish; Abstract available in Spanish from the publisher).

16. Lopez R, Garrido E, Vazquez G, Piña P, Pérez C, Alvarado I and Salcedo M: A subgroup of HOX Abd-B gene is differentially expressed in cervical cancer. Int J Gynecol Cancer 16: 1289-1296, 2006.

17. Mustafa M, Lee JY and Kim MH: CTCF negatively regulates HOXA10 expression in breast cancer cells. Biochem Biophys Res Commun 467: 828-834, 2015.

18. Carrera M, Bitu CC, de Oliveira CE, Cervigne NK, Graner E, Manninen A, Salo T and Coletta RD: HOXA10 controls proliferation, migration and invasion in oral squamous cell carcinoma. Int J Clin Exp Pathol 8: 3613-3623, 2015.

19. Tang W, Jiang Y, Mu X, Xu L, Cheng W and Wang X: MiR-135a functions as a tumor suppressor in epithelial ovarian cancer and regulates HOXA10 expression. Cell Signal 26: 1420-1426, 2014.

20. Fambrini M, Bussani C, Sorbi F, Pieralli A and Cioni R: Methylation of the HOXA10 homeobox gene promoter is associated with endometrial cancer: A pilot study. J Obstet Gynaecol 33: 519-520, 2013.

21. Bruins HM, Skinner EC, Dorin RP, Ahmadi H, Djaladat H, Miranda G, Cai J and Daneshmand S: Incidence and location of lymph node metastases in patients undergoing radical cystectomy for clinical non-muscle invasive bladder cancer: Results from a prospective lymph node mapping study. Urol Oncol 32: $13-24,2014$.

22. Abdollah F, Gandaglia G, Thuret R, Schmitges J, Tian Z, Jeldres C, Passoni NM, Briganti A, Shariat SF, Perrotte P, et al: Incidence, survival and mortality rates of stage-specific bladder cancer in United States: A trend analysis. Cancer Epidemiol 37: 219-225, 2013.

23. Dodurga Y, Tataroglu C, Kesen Z and Satiroglu-Tufan NL: Incidence of fibroblast growth factor receptor 3 gene (FGFR3) A248C, S249C, G372C, and T375C mutations in bladder cancer. Genet Mol Res 10: 86-95, 2011.

24. Cheng W, Jiang Y, Liu C, Shen O, Tang W and Wang X: Identification of aberrant promoter hypomethylation of HOXA10 in ovarian cancer. J Cancer Res Clin Oncol 136: 1221-1227, 2010.

25. Srivastava P, Mandhani A, Kapoor R and Mittal RD: Role of MMP-3 and MMP-9 and their haplotypes in risk of bladder cancer in North Indian cohort. Ann Surg Oncol 17: 3068-3075, 2010 . 
26. Nakopoulou L, Gakiopoulou H, Zervas A, Giannopoulou I, Constantinides C, Lazaris AC, Liapis H, Kyriakou G and Dimopoulos C: MMP-3 mRNA and MMP-3 and MMP-1 proteins in bladder cancer: A comparison with clinicopathologic features and survival. Appl Immunohistochem Mol Morphol 9: 130-137, 2001.

27. Ricci S, Bruzzese D and DI Carlo A: Evaluation of MMP-2, MMP-9, TIMP-1, TIMP-2, NGAL and MMP-9/NGAL complex in urine and sera from patients with bladder cancer. Oncol Lett 10: 2527-2532, 2015.

28. Jager T, Tschirdewahn S, Vom Dorp F, Piechotta G, Rubben H and Szarvas T: Siliconchiptechnology-based MMP-7 analysis in urine: An option for preoperative identification of lymph node metastasis in bladder cancer. Urologe A 52: 853-858, 2013 (In German).

29. Szarvas T, Jager T, Becker M, Tschirdewahn S, Niedworok C, Kovalszky I, Rübben H, Ergün S and vom Dorp F: Validation of circulating MMP-7 level as an independent prognostic marker of poor survival in urinary bladder cancer. Pathol Oncol Res 17: 325-332, 2011
30. Zhang L, Liu XR, Liu JZ, Song YX, Zhou ZQ and Cao BY: miR-182 selectively targets HOXA10 in goat endometrial epithelium cells in vitro. Reprod Domest Anim 52: 1081-1092, 2017.

31. Xiao ZD, Jiao CY, Huang HT, He LJ, Zhao JJ, Lu ZY and Liu LX: miR-218 modulate hepatocellular carcinoma cell proliferation through PTEN/AKT/PI3K pathway and HoxA10. Int J Clin Exp Pathol 7: 4039-4044, 2014.

(c) (i) This work is licensed under a Creative Commons Attribution 4.0 International (CC BY 4.0) License. 